\title{
Author Correction: The rise and fall of the Old World savannah fauna and the origins of the African savannah biome
}

Ferhat Kaya (D), Faysal Bibi, Indrè Žliobaitè, Jussi T. Eronen, Tang Hui and Mikael Fortelius

Correction to: Nature Ecology \& Evolution https://doi.org/10.1038/s41559-017-0414-1, published online 1 January 2018.

In the version of this Article originally published, each of the five panels in Fig. 5 incorrectly contained a black diagonal line across the plot. This has now been corrected.

Published online: 15 January 2018

https://doi.org/10.1038/s41559-018-0468-8 